\title{
Modelagem no ensino de Física via produção de stop motion, com o computador Raspberry Pi
}

\author{
Modelling in physics teaching via stop motion production with the Raspberry Pi compute \\ Ernani Vassoler Rodrigues*1@, Daniel Lavino ${ }^{2}$ \\ ${ }^{1}$ Universidade de São Paulo, Faculdade de Educação, São Paulo, SP, Brasil \\ ${ }^{2}$ Universidade Federal do Espírito Santo, Núcleo de Tecnologia Assistiva, Vitória, ES, Brasil
}

Recebido em 15 de Janeiro de 2019. Revisado em 25 de Junho de 2019. Aceito em 28 de Julho de 2019.

\begin{abstract}
Neste trabalho apresentamos um aparato de baixo custo para produção de animações quadro a quadro (stop motion) como ferramenta didática no ensino da Física. Dedicado à captura e exibição de stop motions, o aparato é construído com o computador Raspberry Pi e conta com uma interface que permite ao aluno um manuseio simplificado e reprodução imediata de resultados modelados. Apresentamos uma revisão sobre as diferentes ferramentas de modelagem de situações dinâmicas e apresentamos as características que tornam vantajoso o uso de stop motion no ensino da Física. Traçamos um breve histórico da produção de animações quadro a quadro e, então, fazemos uma descrição detalhada da construção do aparato bem como da instalação de um software customizado desenvolvido, a fim de que possa ser replicado para utilização em salas de aula de Física.

Palavras-chave: arte e ciência, modelagem dinâmica, vídeos quadro a quadro.
\end{abstract}

In this work we present a cost effective apparatus for producing frame by frame animation (stop motion) as a didactic tool for Physics teaching. The apparatus dedicated to capture and exhibit stop motion is built with a Raspberry Pi computer and has an interface which allows students to a simplified handling and to an immediate playback of the modeled results. We review different tools for modeling dynamic situations and we also present characteristics that make advantageous the usage of stop motion on Physics teaching. We draw a short historical landscape of frame by frame animation and then we describe in detail how to build the apparatus and how to install a custom dedicated software we developed, in order to enable its replication and use in Physics classrooms.

Keywords: art and science, dynamic modelling, frame by frame video.

\section{Introdução}

Eventos observados no mundo físico ocorrem dinamicamente e têm suas grandezas físicas variando no tempo. As descrições desses eventos, apresentadas em manuais ou livros didáticos de Física, são tipicamente estáticas e por isso se afastam do evento em si. Essa limitação inerente se caracteriza pela ausência de formas de modelagem e reprodução dos eventos, da maneira como são no mundo natural, tais que possam considerar a variação temporal das quantidades físicas envolvidas.

Isso aponta para a necessidade de se considerar a dinâmice $2^{1}$ dos eventos físicos a partir de formas de representação não-estáticas. Uma das soluções mais costumeiramente encontradas em manuais didáticos é a utilização de uma ou várias imagens estáticas sequenciais, indicando uma evolução temporal que, na prática, se congela no tempo por estar fixada à página onde se encontra

\footnotetext{
*Endereço de correspondência: ernanivr@usp.br

${ }^{1} \mathrm{O}$ termo dinâmica, neste trabalho, não invoca as causas das variações de movimento. Para além do tradicional título "Dinâmica", presente nos livros didáticos de Física, usaremos dinâmica sempre nos referindo a variações temporais de grandezas físicas de um evento.
}

impressa. Esse contrassenso pode ser problemático aos estudantes, pois a caracterização estática de um evento dinâmico é reportada como obstáculo para o entendimento dos mecanismos de fenômenos físicos [1].

Buscando formas de superar esse obstáculo, propomos a produção de vídeos quadro a quadro, chamados de stop motion, feita pelos estudantes, como estratégia didática. Defendemos a utilização dessa técnica considerando que, além de ter potencialidades em praticamente todas os temas da Física onde ocorram variações temporais de grandezas, também permite o desenvolvimento de atividades criativas, nas quais os estudantes têm a oportunidade de expressar, por meio da produção desses stop motion, suas concepções acerca da dinâmica do mundo natural e acerca dos mecanismos por trás dos eventos não-estáticos.

Neste trabalho, faremos inicialmente um sobrevoo pelo estado da arte das diferentes formas modelagem de eventos dinâmicos já estabelecidas no ensino de ciências e, particularmente, da Física. Isso localizará o uso de stop motion, explicitando as características que o fazem ser uma ferramenta didática peculiarmente interessante. Para isso, recuperaremos brevemente a gênese da construção de ani- 
mação quadro a quadro e do próprio cinema para, então, apresentaremos nossa proposta de construção de vídeos em stop motion no ensino da Física.

Apresentaremos potencialidades da produção de stop motion como atividade engajadora - à luz de uma base teórica sobre engajamento - e mostraremos como a produção de vídeos com essa técnica opera na interface entre Ciência e Arte.

$\mathrm{Na}$ parte final deste texto, apresentaremos um aparato desenvolvido: uma estação de produção de stop motion, construída com o computador Raspberry Pi. Para essa última, ofereceremos uma espécie de tutorial, permitindo à comunidade docente de Física a reprodução do aparato a custo acessível, de maneira a viabilizar seu uso em sala de aula.

\section{Modelagem de eventos dinâmicos}

O esforço para superar as limitações das representações estáticas de situações dinâmicas passa pela modelagem de fenômenos ou eventos, associados a algum tipo de movimento. Esse tipo de modelagem permite ao aluno algum controle sobre o registro do evento para que possa, posteriormente, proceder uma análise. Assim, é possível que o aluno, a posteriori, veja, reveja, volte ou vá a diante em etapas do evento, podendo obter registros numéricos ou gráficos que permitam avaliar a evolução temporal dos acontecimentos modelados, por meio de alguma linguagem representacional.

Uma das propostas desse tipo é a modelagem via fotografia estroboscópica [2,3, que se vale do registro de sucessivas posições de um ou vários corpos, apresentadas em um mesmo quadro fotográfico. Esse procedimento é feito com lampadas estroboscópicas que acendem e apagam de maneira intermitente, com intervalos de tempo iguais e controlados. Com isso, uma sequência temporal de posições dos corpos é registrada num mesmo quadro.

As fotografias estroboscópicas permitem a captura detalhada das posições dos corpos que estiveram em movimento. Com esse registro, uma vez que exista uma régua de referência junto ao quadro capturado, é possível medir os diversos deslocamentos dos móveis e assim descrever matematicamente as variáveis associadas ao movimento dos corpos.

Outra forma de modelar acontecimentos dinâmicos é a utilização de softwares de videoanálise, tendo possivelmente como seu representante mais conhecido da comunidade docente de Física o Tracker [4,5]. No uso do Tracker, primeiramente registra-se um evento em vídeo. Então, os corpos que estiverem em movimento podem ser acompanhados (seguidos) a partir de um ou vários pixels de referência, e analisados posteriormente. Por exemplo, o aluno pode filmar um lançamento oblíquo de um projétil e em seguida utilizar o Tracker perseguir o movimento do projétil registrado em vídeo. Utilizando-se o Tracker é possível também criar uma régua de referência para, a partir dela, analisar e plotar descrições cinemáticas, curvas e vetores dentre outras oportunas facilidades.

Uma característica comum às duas ferramentas apresentadas acima é que tanto na fotografia estroboscópica quanto na videoanálise com o Tracker os modelos são construídos numa ordem evento $\rightarrow$ registro $\rightarrow$ controle $\rightarrow$ representações. O contraste das duas ferramentas é que no caso do Tracker, o ferramental de análise é automatizado. Isso torna a plotagem de gráficos e os cálculos de variáveis acessíveis a poucos cliques de mouse, no computador. Já as fotografias estroboscópicas oferecem, em um quadro único, todos os pontos de interesse de um movimento capturado, ficando a análise, os cálculos e as plotagens a cargo do analisador, num momento posterior.

Ainda dentro do rol de ferramentas didáticas para modelagem de eventos dinâmicos, pode-se incluir os modelos virtuais, como as simulações interativas do PhET [6,7]. O PhET simula, em ambiente virtual, experimentos sobre temas da Física e permite o controle de variáveis relevantes, bem como a visualização imediata dos fenômenos simulados. Os temas do PhET são claramente delimitados e são apresentados em cenários previamente construídos, colocados à disposição de professores e alunos. Uma vantagem de utilização do PhET é o acesso virtual a experimentos que demandariam custo de montagem e expertise de operação em um laboratório físico. Entretanto, uma limitação do PhET é que os cenários pré-fixados e as situações previamente determinadas não permitem que aluno a extrapole as fronteiras estabelecidas pelos temas propostos.

Também como ferramenta de geração de modelos físicos virtuais, destacamos a Algodoo 8, 9], atual mantenedora do descontinuado projeto Phun 10,11. Nessa, os cenários e os elementos móveis são construídos de maneira que o estudante gere um universo que opera sob as leis da Física. Por exemplo, o aluno pode montar uma situação na qual a transmissão de um movimento circular com engrenagens provoca uma colisão entre corpos rígidos que entram em queda com arrasto do ar e que, por fim, perturbam um fluido. O aluno controla as variáveis envolvidas, podendo modificar o arrasto ou o valor da aceleração da gravidade para então explorar diferentes resultados na situação construída. Com isso, o leque de possibilidades dos modelos feitos com a Algodoo não é limitado por um tema específico. Nesse software, os modelos são construídos numa ordem cenário $\rightarrow$ elementos $\rightarrow$ controle $\rightarrow$ evento.

As ferramentas de modelagem apresentadas acima, encontram-se razoavelmente estabelecidas e são de grande viabilidade didática. Podemos agrupá-las em duas categorias. Numa delas, seja por fotografia estroboscópica, seja por videoanálise, um acontecimento no mundo físico é transformado em uma informação visual: o aluno opera o aparato capturando o acontecimento para então proceder análises que permitam explorar o fenômeno. Atividades que se valem desse processo variam desde a verificação da trajetória de um lançamento oblíquo 12 até a análise 
do experimento de Millikan no qual, a uma certa ddp entre as placas carregadas, a força resultante sobre as gotas de óleo é nula $[13$. Na outra categoria, tanto com o PhET quanto com o Algodoo, os acontecimentos não são capturados, mas sim gerados virtualmente. Então o aluno pode explorar os desdobramentos do fenômeno. A viabilidade didática dessa segunda categoria pode ser vista em propostas que vão do ensino de eletricidade 14 até a exploração das leis de Newton [15], dentre outras possíveis.

Não buscamos criar uma tensão acerca das formas de uso das diferentes ferramentas de modelagem apresentadas. Mas, ao descrevê-las e ao delinearmos suas fronteiras, podemos posicionar a modelagem via produção de stop motion como uma adição ao rol de possibilidades para modelagem de eventos dinâmicos no ensino da Física.

Na produção de um stop motion a captura de imagens quadro a quadro se assemelha, em parte, à primeira categoria acima, no sentido de que a informação é capturada do mundo físico para o computador. E também se assemelha à segunda categoria, quando observamos a simulação de fenômenos físicos, como no PhET, e a liberdade de construção de situações, como no Algodoo.

Contudo, na produção de um stop motion a peculiaridade está no fato do aluno decidir o que deve acontecer nos quadros subsequentes, para que a animação ocorra. Entre um quadro capturado e o quadro seguinte, tem-se a evolução de um incremento de tempo da animação. Cada móvel do modelo precisa ter sua sua posição ajustada e o reposicionamento dos elementos móveis demanda plausibilidade. É na busca pela plausibilidade da animação que se faz necessário o uso de uma teoria física de fundo, inerente ao fenômeno a ser animado, tal que permita uma animação minimamente coerente com a natureza.

É nesse processo que o aluno ativa seus conhecimentos e os elabora, de modo a construir um stop motion cujos movimentos sejam fisicamente plausíveis. Isso não nega a possibilidade de os alunos extrapolarem intencionalmente os limites da plausibilidade. Mas em todo caso, a organização do quadro seguinte sempre dependerá de uma tomada de decisão: produzir um stop motion exige que os alunos decidam de que forma a sequência de quadros estáticos será transformada em movimento. Esse processo recupera os primórdios da produção cinematográfica, conforme mostraremos a seguir.

\section{Stop motion: origens e possibilidades}

\subsection{Breve histórico}

O início das produções em stop motion se confunde com o início do próprio cinema. É factível inclusive colocar o desenvolvimento do stop motion como uma gênese do cinema. Olhando para os meados do século XIX, havia um movimento de inventores e cientistas na busca por formas de representação dos movimentos. Essas representações se valiam de quadros estáticos, sequenciais, exibidos su- cessivamente numa taxa maior do que nossa percepção poderia detectar e essa era a essência da simulação do movimento.

À época do alvorecer do cinema, na segunda metade do século XIX, o movimento simulado impressionava. Fotografias tiradas em sequência serviam para registrar e analisar movimentos de animais [16]. Artefatos capazes de simular movimentos também serviam para divertiento das pessoas. Esses artefatos eram classificados como brinquedos filosóficos 17, análogos aos instrumentos filosófi$\cos$, tais quais luneta e microscópio, mas com a diferença de que esses últimos eram dedicados exclusivamente à examinação da natureza.

Alguns dos brinquedos filosóficos de simulação de movimento datam da era pré-cinema, considerando-se a inauguração da era do cinema como a primeira exibição cinematográfica, feita pelos irmãos Lumière em 1895. Anterior à exibição dos Lumière, Charles-Émile Reynaud registrara um cilindro com espelhos em sua geratriz que, ao girar, refletia um conjunto sequencial de desenhos feitos na parede interna de outro cilindro concêntrico. O brinquedo filosófico de Reynaud era chamado Praxinoscópio (Figura 1, A) e simulava o movimento dos desenhos em sequência 18. Mas o aparato de Reynaud tem antecessores. Em meados da década de 1830, William Horner construíra um cilindro com rasgos igualmente espaçados em sua geratriz. Na face interna do cilindro, uma sequência de imagens era posicionada. Quando o cilindro girava, essas imagens eram vistas através dos rasgos na geratriz, simulando o movimento. O brinquedo filosófico de Horner ficou conhecido como Zootropo (Figura 1, B) 17]. Mas cerca de um ano antes de Horner, Joseph Plateau construíra o Phenakistoscópio [19] e de maneira semelhante, no mesmo ano, Simon Stampfer propunha o Disco Estroboscópico [17. Ambos os aparatos, de Plateau e de Stampfer, posicionavam os desenhos sequenciais nos setores circulares de um disco. Rasgos radiais próximos à borda, igualmente espaçados, permitiam que se visse por um espelho, ou por outro disco idêntico, a sequência de imagens numa taxa maior do que a percepção humana é capaz de detectar, simulando o movimento (Figura 1, C).

A exibição cinematográfica dos irmãos Lumière, então, culmina uma época em que sucessivos avanços foram obtidos na simulação do movimento a partir de sequências de quadros estáticos. A sedimentação das técnicas de projeção cinematográfica permitiu que J. Stuart Blackton, poucos anos depois da primeira exibição dos Lumière, utilizasse uma sequência de fotografias para produzir o que seria, possivelmente, o primeiro filme stop motion conhecido: a obra The Humpty Dumpty Circus [20].

A partir da obra de Blackton, a evolução das animações em stop motion se dá não apenas paralela à evolução do cinema, mas como uma evolução do próprio cinema. Produzir animações com desenhos sobre os quadros do cinema era a forma utilizada para gerar efeitos especiais na era pré-digital. Isso permitia deslocar a noção de 
realidade nas exibições cinematográficas. Associado ao potencial criativo dos produtores, o cinema apresentava realidades inéditas e improváveis.

O uso de realidades improváveis, que hoje reconhecemos sem muito esforço como gênero cinematográfico da ficção, construídas com efeitos quadro a quadro, tem um marco no trabalho de Georges Méliès com as obras La Lune à un mètre (A Lua a um metro) e Voyage dans la Lune (Viagem à Lua), ambas da virada do século XIX para o século XX. A realidade improvável que essas obras exploravam, viria a se concretizar algumas décadas depois, com a corrida espacial. Outras ramificações dos processos de animação quadro a quadro incluíram animações feitas com massa de modelar (claymation), animações com sombras, animações com recortes de papel e os populares desenhos animados 21.

Por trás de todos esses processos de produção de animações, desde os brinquedos filosóficos até o cinema atual, está um princípio mais polêmico e menos exato do que desejaríamos: a persistência visual. Persistência visual é um intervalo de tempo dentro do qual duas imagens não podem ser diferenciadas, sendo então interpretadas como uma continuidade, como movimento. O intervalo de tempo da persistência visual é definidor de uma taxa de exibição dos quadros ou fps (frames per second), que deve ser utilizada para que tenhamos o movimento percebido a partir dos quadros estáticos.

Qualquer afirmação cabal sobre o valor do tempo de persistência visual, perde força diante da polêmica que o cerca. Galifret [19 retoma os primórdios das produções de cinema, quando ${ }^{1} / 10 \mathrm{~s}$ para o tempo de persistência visual, era tido como certo. Mas os experimentos feitos no século XIX para se determinar esse valor mostraram que, dependendo de diferentes fatores-estímulo como luminosidade, geometria do objeto e a relação entre o objeto e seu entorno, faziam variar o tempo de persistência visual. Anderson e Anderson 22$]$ mostram como o aumento da taxa de exibição de quadros pode tornar o movimento mais suave ao expectador. Mas pontuam a influência de movimentos relativos entre objetos no tempo de persistência

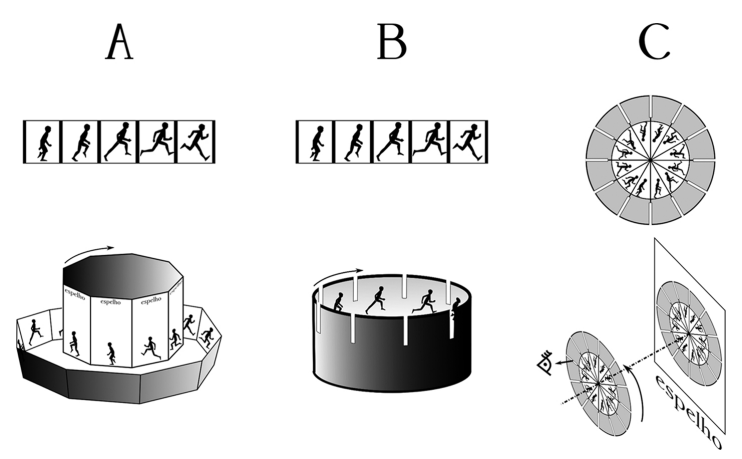

Figura 1: Brinquedos filosóficos com simulação de movimento: Praxinoscópio de Reynaud (A), Zoótropo de Horner (B) e Phenakistoscópio de Plateau ou Disco Estroboscópico de Stampfer (C). visual. As condições do entorno do objeto, chamadas de dimensão espaçotópica, e a de luminosidade impressa na retina, a dimensão retinotópica, também são postas por Breitmeyer et al [23 como influenciadoras da persistência visual.

Podemos ver que a definição do tempo de persistência da visão, e também da taxa fps adequada para a produção de um stop motion razoável, é historicamente problemática. É possível se construir 1s de animação com 10 quadros ou com 24 quadros ou com quantos mais fps se deseje. A suavidade do movimento resultante depende do número de quadros. A indústria cinematográfica utiliza um padrão de ${ }^{1} / 24 \mathrm{~s}$ como suficiente para simulação de movimento, mas faz com que cada quadro seja exibido duas ou três vezes na tela, a fim de suavizar a percepção do movimento 19].

A utilização de uma grande taxa de quadros por segundo tem como efeito final positivo uma transição mais suave entre sucessivas posições dos corpos animados. Mas em contrapartida, a captura se torna um processo demorado, o que pode ser algo negativo, se pensarmos em sua utilização em uma sala de aula. No aparato que estamos propondo neste trabalho, utilizamos como padrão uma taxa de $10 \mathrm{fps}$, ou seja, a cada 10 imagens capturadas os estudantes terão produzido $1 \mathrm{~s}$ de vídeo. No entanto, no aparato desenvolvido para este trabalho, essa taxa pode ser modificada para mais ou para menos, utilizando-se as teclas $N$ e $M$ do teclado do computador, conforme detalhado em documentação disponível junto ao aplicativo desenvolvido.

Com o uso de 10 fps, abrimos mão de uma animação suavizada ou profissionalizada dos modelos, primeiro por buscarmos tornar o tempo de captura mais ágil, privilegiando a viabilidade didática da atividade, uma vez que, tipicamente, no ensino básico as aulas de Física não têm duração maior do que duas horas; depois, por entendemos que os resultados de baixa tecnologia (low-tech), no ensino de ciências, são importantes para explicitar aos alunos o tamanho do esforço empreendido no processo de refino de produtos científico-tecnológicos considerados de alta tecnologia (high-tech).

A produção de animações quadro a quadro, nossos stop motions, congrega um leque de conhecimentos artísticos e científicos que se refinaram ao longo do tempo, tornando o cinema o que é atualmente. Tais conhecimentos podem ser pano de fundo para desenvolvimento de projetos que permitam uma convergência de diferentes disciplinas e que usem os stop motions como atividade transversal. É fato que estamos apresentando uma técnica e um aparato desenvolvido especificamente para o uso da técnica, voltados à modelagem de fenômenos físicos. No entanto, eixos temáticos como Imagem e Som, por exemplo, podem ser a via dentro da qual disciplinas como Arte, História e Física caminhem de mãos dadas, tal qual o fizeram no tempo histórico. 


\subsection{Stop motion e ensino de ciências}

Temos comparado acima diferentes formas de modelagens e diferentes papeis do aluno ante cada uma delas. Incluímos a construção de animações stop motion e ressaltamos que nessa forma de modelagem o aluno tem liberdade de idealizar cenários e de escolher os elementos que irá utilizar na animação, sejam eles desenhos, objetos, modelos com massa de modelar, modelos cortados em papel ou tecido, dentre outros. Lançando mão dos conhecimentos que possui, o aluno pode expressá-los na forma de um registro visual animado, modelando um fenômeno natural e discutindo sobre ele.

Considerando o contexto do ensino de ciências, a produção de animações stop motion já foi sugerida por Garry Hoban 24], focando especialmente em animações com massa de modelar. Em um trabalho posterior, Hoban 25. analisa a utilização de uma forma simplificada de produção de animações quadro a quadro, procedida por professores em formação para aulas de ciências do ensino fundamental.

Hoban salienta a facilitação no aprendizado de ciências em várias fases da atividade de modelagem stop motion: durante o planejamento da atividade, os conceitos são evocados e separados em elementos que sirvam à construção de cada quadro; durante a construção do modelo, as evoluções temporais são construídas incrementalmente, permitindo ao aluno refletir sobre o fenômeno em pequenos passos; e ainda, a possibilidade de reconstruir o modelo, faz com que a modelagem stop motion seja um processo iterativd ${ }^{2}$, ou seja, cada ciclo de reconstrução demanda uma reflexão profunda por parte do aluno acerca de quais são os aspectos relevantes ao fenômeno e quais devem ser deixados com menos importância.

Acatamos essas vantagens pontuadas por Hoban, que nos levam a concluir que esse tipo de atividade pode ser vantajosa em qualquer ciclo escolar em ciências. Podemos ainda acrescentar à lista de vantagens de Hoban o fato de que os stop motions construídos pelos alunos evidenciam quais são as concepções alternativas estão mais presentes. Diante delas, o professor pode propor discussões acerca dos mecanismos por trás dos fenômenos estudados, ajudando os alunos a superarem eventuais barreiras.

As potencialidades do uso do stop motion no ensino de ciências são vistas em outros trablhos, como Bossler 26] que utiliza a animação quadro a quadro com massa de modelar para ensino de Biologia, Pereira 27 que discute a importância da animação no letramento digital e Barbosa 21], que defende o uso da animação, num sentido amplo, como metodologia de ensino. Na esteira desses trabalhos, defendemos o uso do stop motion como abordagem viável para o ensino de Física e ainda como

\footnotetext{
2 iterações no sentido de repetições sucessivas, dotadas de pequenos ajustes que são fundamentais para o processo de design e refino do modelo, tal que os estudantes possam dirimir sutilezas que muitas vezes separam as concepções científicas aceitas daquelas do senso comum
}

atividade potencialmente engajadora, conforme mostraremos a seguir.

\subsection{Stop motion e engajamento}

$\mathrm{Na}$ abordagem de ensino com modelagem stop motion, o estudante encontra um ambiente com liberdade criativa para expressar suas formas de compreensão da natureza. Essa liberdade é essencial ao engajamento dos alunos. Para evitar a polissemia do termo "engajamento", pontuaremos a visão que estamos utilizando. Azevedo e colaboradores $[28$ se apoiam na teoria do Flow, de Csikszentmihalyi [29] para definir as características do engajamento numa atividade escolar.

Uma performance engajada permite uma experiência escolar fluida e focada. Mas, para que isso seja possível, é necessário que o participante se depare com uma atividade claramente estruturada. Uma atividade claramente estruturada deve contemplar: (a) um conjunto claro de regras, tal que o participante tenha um campo de ação bem definido; (b) espaço suficiente para autoexpressão, dentro dos limites de ação que a atividade promova, tal que o participante possa controlar os resultados obtidos por seus esforços e $(c)$ suficiente feedback para que o participante possa continuamente avaliar onde e o quanto progrediu na atividade, algo que o mantém interessado em continuar tentando melhorar.

As premissas da teoria psicológica do Flow, que pressupõem um engajamento do indivíduo, são usadas por Azevedo e colaboradores como premissas para também sustentar o engajamento grupal. Isso significa que a presença de uma atividade claramente estruturada é fundamental para o engajamento de uma classe de alunos. E nesse sentido, a produção de stop motions carrega as características de uma atividade claramente estruturada:

- Na construção de stop motion, o estudante tem, bem definido, qual é o número de quadros (fotografias a serem tiradas) que formarão $1 \mathrm{~s}$ de animação. Juntando-se os conceitos da Física, trazidos pelo estudante com o auxílio do professor, para a construção do modelo, tem-se a regra do jogo $(a)$;

- Como a construção dos quadros é livre, o aluno pode decidir sobre o cenário e os elementos que serão modelados, tendo amplo espaço para autoexpressão $(b)$;

- Cada vez que uma pequena animação é concluída, seu resultado pode ser visto imediatamente. Na presença do professor que utilize esse resultado para discutir possíveis inconsistências, o estudante tem um imediato feedback (c) da atividade.

Pontuando essas características, incluímos o potencial para o engajamento como outra vantagem na utilização de modelagem via da produção de stop motion. 


\section{Aparato de produção de stop motion}

A utilização de microcontroladores que permitem uma interface entre o mundo físico e o mundo digital configura uma corrente crescente no ensino de ciências. Possivelmente o aparato mais representativo em propostas para o ensino são as placas controladoras Arduíno, como a UNO ou a Leonardo, dentre outras. O Arduíno vem sendo amplamente utilizado em propostas didáticas de Física. Desde atividades com circuitos elétricos [30], oscilador amortecido e transferência de calor 31] ou medição experimental do valor da aceleração da gravidade 32 .

O baixo custo e a operação relativamente simples, colocam o Arduíno com um status especial nas propostas que mesclam experimentos científicos, robótica e tecnologias de controle e automação. Mas o Arduíno não é um computador completo, não hospeda um sistema operacional completo e, por isso, mesmo sendo uma excelente interface entre o mundo físico e o mundo digital, não contém as capacidades de processamento de dados que aquilo que reconhecemos como um computador completo possui.

A alternativa que oferece as funcionalidades de um computador completo, que é de baixo custo e que ainda pode atuar como interface entre os mundos analógico e digital é o computador Raspberry Pi [33], da fundação britânica de mesmo nome, mostrado na Figura 2. Por isso, o Raspberry Pi se mostrou o hardware adequado para construirmos nossa estação de produção de stop motion com finalidade didática em Física.

Embora seja menos popular que o Arduíno, o Raspberry Pi começa a conquistar espaço em propostas multiárea, como medição de espectro de radiofrequência [34], sistema de monitoramento cardíaco com baixo custo [35] ou ainda para controlar remotamente os equipamentos de laboratório de Física 36].

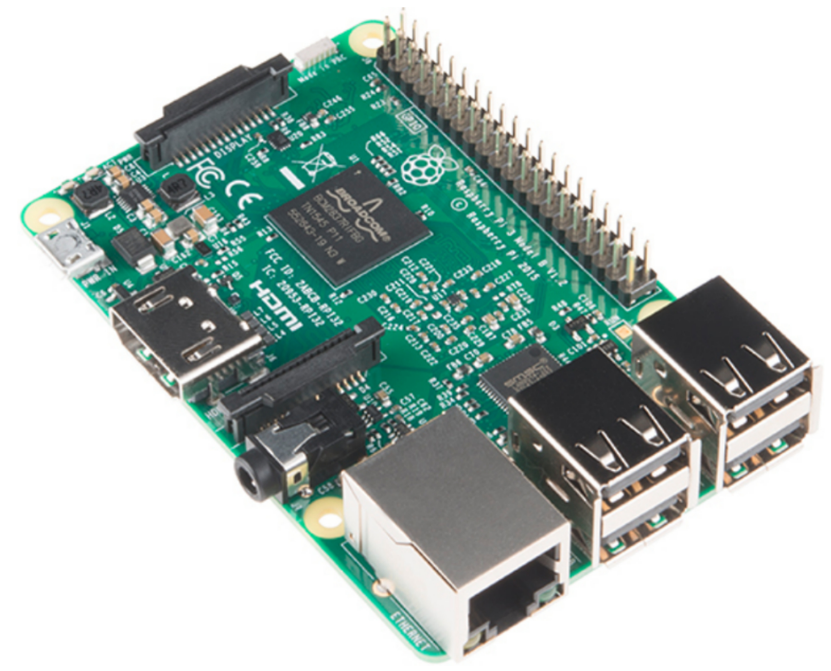

Figura 2: Computador portátil Raspberry $\mathrm{Pi}$, modelo 3, utilizado no aparato construído.
O Raspberry Pi é um computador e um controlador. Isso o faz ser também uma ferramenta de interesse, como aparato didático em aulas de ciências [37, 38. No presente trabalho, construímos uma estação de captura de stop motion conectando uma webcam ao Raspberry $\mathrm{Pi}$ e acoplando botões às portas analógicas, que permitem captura de quadros e reprodução imediata dos vídeos. Os botões permitem que o aluno reproduza e reinicie um modelo sem precisar recorrer à interface computacional para isso. A fim de que os quadros capturados possam ser vistos imediatamente, conectamos um monitor de vídeo ao Raspberry Pi.

O layout de captura de stop motion que propomos é inspirado em duas exibições existentes em dois diferentes museus de ciências situados na região conhecida como do Vale do Silício, no estado da Califórnia nos Estados Unidos: o Lawrence Hall of Science [39], museu que homenageia o físico laureado Ernest Lawrence, e o Exploratorium [40], museu idealizado e fundado pelo físico Frank Oppenheimer.

Embora nesses museus, o aparato de captura de stop motion não tenha função exclusivamente didática, essas duas instituições mantêm tais atividades à disposição do público, confirmando o potencial de engajamento que a produção de stop motion oferece. Ainda, a produção de stop motion se alinha com a perspectiva hands-on [41] desses museus. Nessa perspectiva, o aprendiz é o centro do processo e a aproximação entre Ciência e Arte, bem como o uso mesclado de diferentes mídias, criam ambientes que ativam os sentidos dos participantes [42], algo fundamental à construção de significados.

No entanto, as exibições que inspiraram nossa proposta utilizam aparatos de captura e reprodução de stop motion que não são nem construídos com software gratuito nem com computador de baixo custo. Então, as contribuições do presente trabalho são também a acessibilidade de construção do hardware e a gratuidade do software que desenvolvemos, dedicado ao projeto. Buscamos, com isso, trazer para dentro da sala de aula uma versão adaptada daquilo que centros de ciências estabelecidos no cenário internacional já utilizam como exibição hands-on.

$\mathrm{O}$ aparato consiste de um estação de trabalho que pode ser colocada sobre uma mesa, constando de um computador Raspberry Pi (Figura 3, A) conectado a uma webcam (Figura 3, B) e a um monitor de computador (Figura 3, C). Na haste que sustenta a câmera, uma fita de LED é posicionada (Figura 3, D) para iluminar o modelo a ser capturado.

Próximo ao aluno, são posicionados quatro botões para operação (Figura 3, E). Esses botões são conectados às portas analógicas do Raspberry Pi. Verticalmente abaixo da câmera, é colocada uma prancha de captura (Figura $3, \mathrm{~F}$ ), que sugerimos que seja quadriculada para que os elementos do modelo de construção do cenário possam ser posicionados a cada quadro com alguma referência de medida. 


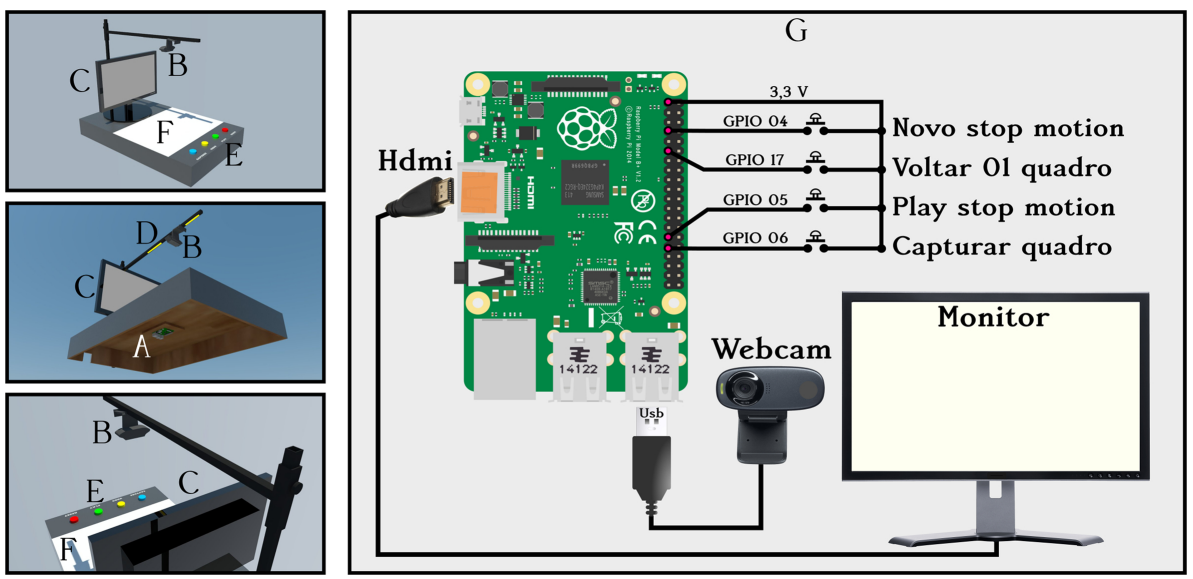

Figura 3: Montagem do aparato. À esquerda, três vistas em perspectiva: A - Raspberry Pi, fixado ao fundo da prancha; B - Webcam no pedestal, acima da prancha de captura; C - Monitor de vídeo, à frente do modelador; D - Fitas de LED para iluminação da prancha; E - Botões de captura; F - Prancha de captura. À direita (G), o esquema de conexões com o Raspberry Pi.

A escolha do design do aparato, em formato de mesa de captura, semelhante às mesas copiadoras (ou copy stand) utilizadas por fotógrafos, posiciona a câmera verticalmente acima do quadro a ser capturado. Essa opção foi feita para permitir uma melhor ergonomia dos estudantes, que podem se posicionar sentados à frente do quadro a ser montado e também da tela, onde o resultado é imediatamente visualizado. Também pela portabilidade do aparato, que pode ser levado de uma sala de aula a outra, pela melhor estabilidade dos quadros, uma vez que os elementos fixos terão sua posição mantida em relação à câmera, pela conveniência de montagem dos quadros a serem capturados, uma vez que os elementos podem repousar sobre a prancha de captura e ainda para minimizar o efeito de paralaxe no momento da captura.

Os itens necessários para reprodução do aparato construído, são:

- Computador Raspberry Pi Model 3, com fonte

- Monitor de computador

- Webcam Usb

- 04 Botões do tipo push/pulse

- cabos

- Fita de LED, com fonte

A fita de LED é importante para que os quadros a serem animados sejam adequadamente iluminados. Mas pode ser substituída por qualquer fonte luminosa disponível ou pode mesmo ser dispensada, caso as animações sejam feitas em um ambiente abundantemente luminoso.

O Raspberry Pi utiliza um sistema operacional Linux para seu funcionamento. A instalação do sistema operacional é feita por um cartão de memória e possui um passo a passo detalhado no site do projeto Raspberry $\mathrm{Pi}$. A distribuição Linux utilizada no aparato que propomos é a Raspbian [43].

Uma vez feita a instalação do sistema operacional, o Raspberry Pi já funcionará como um computador normal, podendo navegar na internet e executar tarefas que qualquer outro computador ordinário poderia. Para o funcionamento do aparato, conforme propusemos, foi desenvolvido um aplicativo 44 em linguagem Python, dedicado, de código aberto, que está disponibilizado em repositório digital, com instruções de uso.

Uma vez baixado, basta executar o aplicativo desenvolvido que o Raspberry Pi já estará se comportando como um aparato de captura e reprodução de stop motion. Embora seja necessário o uso de mouse e de teclado para a instalação do sistema operacional e para download e execução do aplicativo, uma vez que os componentes estejam conectados conforme mostrado na Figura 3 o teclado e o mouse são dispensados e o aparato funciona apenas com os botões dedicados, conectados às portas analógicas do Raspberry $\mathrm{Pi}$. Isso para que, durante a atividade, os alunos possam se concentrar em modelar o fenômeno de interesse, sem a necessidade de operar o computador em si.

Uma característica do aplicativo, que é de interesse em seu uso didático, é a apresentação de imagens em camadas semi-transparentes, que permitem a discussão das posições anteriores dos móveis da animação. Após capturar um certo quadro, os cinco quadros anteriores podem ainda ser vistos, na mesma tela, em transparência gradual, de modo a oferecer uma referência de continuidade do movimento. Também uma fita contendo os últimos quadros capturados é apresentada no rodapé da tela, indicando a sequência dos incrementos do movimento animado, conforme mostrado na Figura 4

Embora estejamos propondo um design para a estação de produção de stop motion, seguimos uma filosofia de código aberto, o que permite extrapolações e as adaptações do aparato a outras formas de uso. A câmera pode ser reposicionada de acordo com a conveniência da atividade, seja mirando um sistema real, como uma bicicleta para construção de um stop motion acerca das transmissões do movimento circular, seja mirando uma prancha de captura alternativa, como ou um quadro mar- 


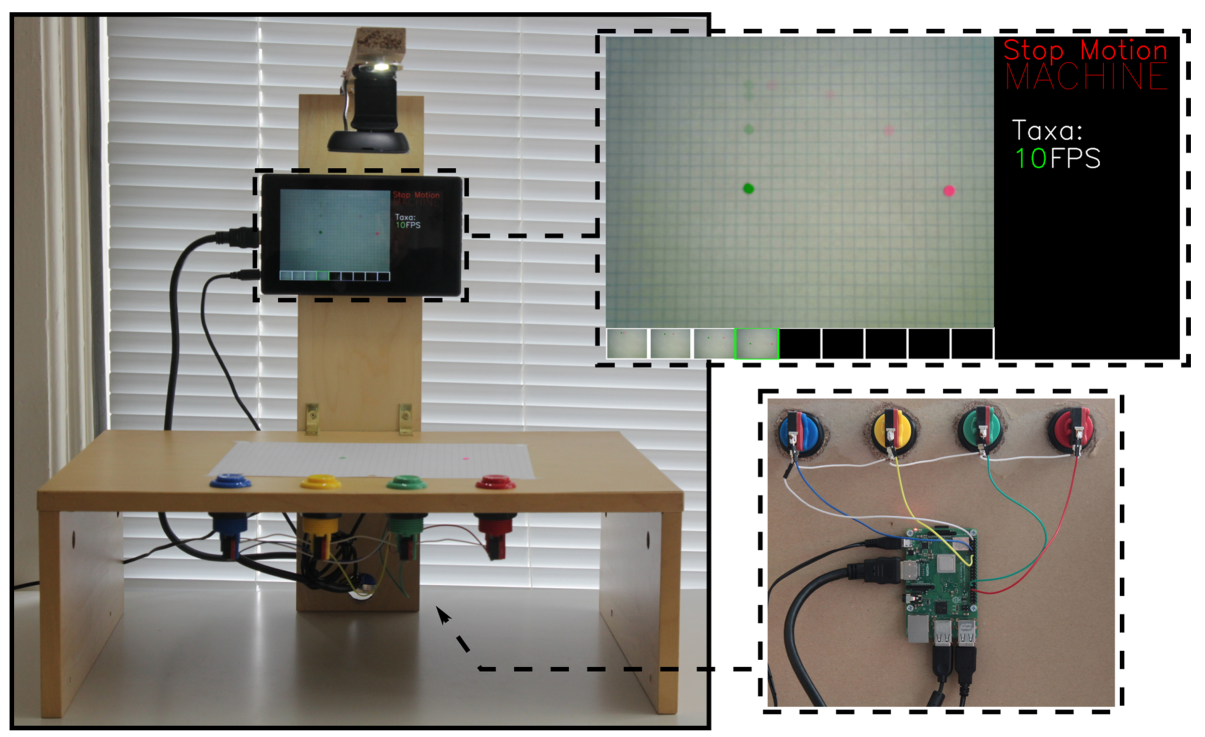

Figura 4: Aparato em funcionamento (à esquerda), animando uma queda livre e um lançamento horizontal, simultâneos. À direita, a tela de trabalho do aplicativo (superior) e as conexões do Raspberry $\mathrm{Pi}$ junto aos botões de captura (inferior).

cador na parede, no qual desenhos podem ser animados. Também os botões de captura podem ser dispensados, caso não estejam disponíveis, tendo como alternativa o uso de teclas específicas em um teclado de computador, conforme detalhado na documentação publicada junto ao aplicativo, em repositório. Ainda, o código fonte do aplicativo encontra-se disponível e aberto, permitindo seu desenvolvimento.

\subsection{Um exemplo de atividade com stop motion}

Como encaminhamento didático, propomos a produção de stop motion para animação das variáveis cinemáticas do movimento harmônico simples (MHS) a partir da projeção das grandezas do movimento circular uniforme (MCU) de uma partícula, sobre um dos eixos coordenados. A atividade é proposta para uma aula de 50 minutos de duração e é dividida em três etapas: o planejamento do modelo, o planejamento dos quadros e a captura dos quadros.

Planejamento do modelo: é nesta primeira etapa que se faz a primeira ativação dos conhecimentos que sejam relevantes à situação. Se o MHS será animado a partir da projeção do MCU, as grandezas fundamentais da cinemática do MCU, que serão projetadas, devem ser selecionadas. Nesta etapa, é necessário identificar quais são as variáveis de interesse que serão trazidas para o modelo. A elongação da partícula em MHS como projeção da posição angular de uma partícula em MCU; a velocidade da partícula em MHS como projeção da velocidade tangencial, de módulo constante, de uma partícula em MCU; e a aceleração da partícula em MHS, como projeção da aceleração radial, de módulo constante, de uma partícula em MCU. A respeito da estruturação da atividade, recuperando a perspectiva do engajamento apresentada acima, é nesta etapa que são identificadas as primeiras regras do jogo.

Planejamento dos quadros: o aluno aqui escolhe quais elementos serão fixos (cenário) e quais serão móveis (partículas, corpos, representações de grandezas, etc). Ainda, por qual processo os elementos que representarão as variáveis serão construídos e colocados no modelo. Isso é de livre criação e livre escolha do aluno, que selecionará os materiais que julgue mais adequados. Como atividade estruturada, a autoexpressão é valorizada nesta etapa, a segunda característica da perspectiva do engajamento que apresentamos.

Sugerimos para esta atividade um cenário desenhando a lápis, contendo uma circunferência com doze posições angulares marcadas, igualmente espaçadas, para o MCU e um eixo coordenado, fora da circunferência, indicadas as posições de máxima elongação e a origem. Então, cada modelo terá um ciclo construído com doze quadros, referentes às posições angulares destacadas.

Mantendo o aspecto low-tech mencionado anteriormente, sugerimos o uso de recortes em papel cartão colorido, como elementos móveis. Dois pequenos círculos em cores diferentes, representando uma partícula em MCU e outra em MHS. Setas recortadas em papel, que representarão os vetores velocidade e aceleração. Para o MCU, um tamanho único. Para as projeções no MHS, três tamanhos distintos, um de mesmo módulo do vetor de tamanho único do MCU, isso para as fases cujas projeções sejam máximas e outras duas, com tamanhos adequados às fases cujas projeções sejam equivalentes a $\frac{\pi}{6}$ e $\frac{\pi}{3}$, que podem ser recortadas com auxílio de um esquadro, além de tiras de papel para representar linhas de projeção.

Captura dos quadros: nesta etapa há uma nova ativação dos conhecimentos, agora referentes aos processos 
inerentes ao MCU, como a constância da taxa do deslocamento angular e suas relações de projeção com o MHS, a cada quadro, tais quais elongações de velocidade e aceleração máximas ou nulas. Nesta etapa, busca-se a plausibilidade do movimento. O stop motion pode ser tocado a cada acréscimo de incremento para eventuais ajustes até que se conclua a animação de um ciclo inteiro. Uma animação em stop motion, semelhante à atividade sugerida, é disponibilizada 45] como exemplo.

Como o aparato permite que, a qualquer instante, a animação seja tocada, o aluno encontra a terceira característica da atividade estruturada para o engajamento, o feedback, podendo avaliar sua animação e podendo se guiar pelas camadas semitransparentes apresentadas na tela de trabalho do aplicativo (Figura 5), retornar de quadro em quadro para correção e ajuste das posições dos elementos móveis ou mesmo refazer, do início, o stop motion.

\section{Considerações finais}

Apresentamos uma proposta de uso didático de um aparato de captura e reprodução de stop motions, construído com um computador de baixo custo e utilizando software gratuito, desenvolvido especificamente para a função. O aparato, destinado ao ensino da Física, amplia o leque de possibilidades de modelagem, permitindo que o aluno construa eventos dinâmicos a partir da captura quadros estáticos de incrementos do movimento.

A construção de stop motions permite que o aluno expresse, na forma de uma produção visual, suas concepções acerca do fenômeno natural animado. O processo recupera aspectos dos brinquedos filosóficos, que revisamos, aproximando a exploração da natureza e o divertimento, bem como os domínios das Ciências e das Artes. Na produção de stop motions o estudante é incentivado a construir, a partir de um mundo imaginário, uma representação animada da realidade física. Ao fazer isso, o estudante ativa seus conhecimentos e pode refinar suas concepções acerca do fenômeno animado.

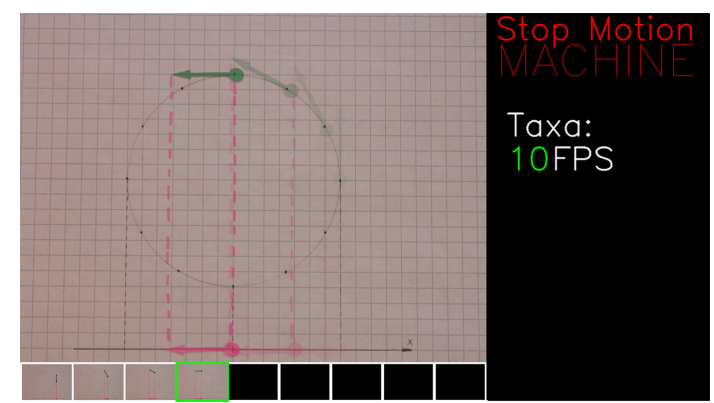

Figura 5: Camadas transparentes e sequência dos quatro primeiros quadros de um stop motion no qual a velocidade de uma partícula em MHS é animada a partir da projeção da velocidade tangencial de uma partícula em MCU, num eixo coordenado.
Por demandar a ativação de uma ou mais concepções que façam o stop motion ser plausível, em cada produção há uma oportunidade de se utilizar os resultados vistos imediatamente na tela para a discussão das teorias físicas que fundamentam o evento animado. Nessas discussões, inconsistências podem ser identificadas e problematizadas.

Eventuais inconsistências ou animações não plausíveis - como posições equidistantes para um móvel cujo movimento seja dotado de aceleração, por exemplo -, podem ser confrontadas com o fenômeno em seu estado natural, pelo uso combinado do stop motion com as outras técnicas de modelagem, como alguma das que apresentamos neste trabalho. Isso amplia o debate em sala de aula e permite o desenvolvimento tanto das concepções dos alunos acerca da natureza, quanto de suas novas representações, expressas em seus stop motions.

\section{Agradecimentos}

Os autores agradecem ao revisor pela leitura, pelas correções e pelas valiosas sugestões e contribuições dadas ao trabalho. O presente trabalho foi realizado com apoio da Coordenação de Aperfeiçoamento de Pessoal de Nível Superior - Brasil (CAPES) - Código de Financiamento 001.

\section{Referências}

[1] A.A. diSessa, Cognition and instruction 10, 105 (1993).

[2] L. Borghi, A. Ambrosis, P. Mascheretti e C.I. Massara, Physics Education 22, 117 (1987).

[3] M.A. Basir, M.R. Alinaghizadeh e H. Mohammadpour, Physics Education 43, 407 (1999).

[4] https://physlets.org/tracker/, acessado em 24/06/2019.

[5] L.K. Wee, C. Chew, G.H. Goh, S. Tan e T.L. Lee, Physics Education 47, 448 (2012).

[6] https://phet.colorado.edu/, acessado em 24/06/2019.

[7] C.E. Wieman e K.K. Perkins, Nature Physics 2, 220 (2006).

[8] http://www.algodoo.com/, acessado em 24/06/2019.

[9] B. Gregorcic e M. Bodin, The Physics Teacher 55, 25 (2017).

[10] J. Koreš, The Physics Teacher 50, 278 (2012).

[11] B.B. Silva, R.B. Oliveira, L.C.P. Rangel, F.R. Leta e M.P. Velloso, in XI International Conference on Engineering and Technology Education (PHUN, Ilhéus, 2010).

[12] A.G. Bezerra Jr, L.P. Oliveira, J.A. Lenz e N. Saavedra, Caderno Brasileiro de Ensino de Física 29, 469 (2012).

[13] A.G. Bezerra Jr, L.P. Oliveira, J.A. Lenz e N. Saavedra, Acta Scientiae 17, 813 (2015).

[14] J.A. Macêdo, A.G. Dickman e I.S.F. Andrade, Caderno Brasileiro de Ensino de Física 29, 562 (2012).

[15] S.R. Silva e C.A.S. Melo, Revista Educação e Emancipação 9, 257 (2016). 
[16] E. Muybridge, The Attitudes of Animals in Motion Illustrated With the Zoopraxiscope (W.M.Clowes and Sons, London, 1882).

[17] N.J. Wade, Journal of the History of the Neurosciences 13, 102 (2004).

[18] R.P. Silva, Cinema e educação (Cortez, São Paulo, 2007).

[19] Y. Galifret, Comptes rendus biologies 329, 369 (2006).

[20] D. Fallman e C. Mousette, Interactions 18, 57 (2011).

[21] M.C. Barbosa, P.H. Santos, M.G. Alcoforado e A.R. Sartore, InfoDesign-Revista Brasileira de Design da Informação 9, 21 (2013).

[22] J. Anderson e B. Anderson, Journal of Film and Video 45, 3 (1993).

[23] B.G. Breitmeyer, W. Kropfl e B. Julez, Acta psychologica 3, 175 (1982).

[24] G.F. Hoban, Teaching Science 51, 26 (2005).

[25] G.F. Hoban, Contemporary Issues in Technology and Teacher Education 7, 75 (2007).

[26] A.P. Bossler e P.Z. Caldeira, Enseñanza de las ciencias: revista de investigación y experiencias didácticas $\mathbf{9 - 1 2}$, 474 (2013).

[27] S. Pereira, C. Pessôa e P. Costa, Comunicação e Sociedade 22, 110 (2012).

[28] F.S. Azevedo, A.A. diSessa e B.L. Sherin, Journal of Mathematical Behavior 31, 270 (2012).

[29] M. Csikszentmihalyi, Flow: The psychology of optimal performance (Harper and Row, New York, 1990).

[30] M.A. Cavalcante, C.R.C. Tavolaro e E. Molisani, Revista Brasileira de Ensino de Física 33, 4503 (2011).

[31] A.R. Souza, A.C. Paixão, D.D. Uzêda, M.A. Dias, S. Duarte e H.S. Amorim, Revista Brasileira de Ensino de Fisica 33, 1702 (2011).

[32] H. Cordova e A.C. Tort, Revista Brasileira de Ensino de Física 38, e2308 (2016).

[33] https://www.raspberrypi.org/ acessado em 24/06/2019.

[34] A. Arcia-Moret, E. Pietrosemoli e M. Zennaro, in Global Information Infrastructure Symposium (IEEE, Trento, 2013).

[35] T. Nagy e Z. Gingl, in Computational Intelligence and Informatics 14th International Symposium (IEEE, Budapeste, 2013).

[36] M.D. Marvin, The Raspberry Pi Embedded Linux Computer as an Alternative Controller for Remote Access Laboratories. Doctoral Thesis, Kent State University, Kent (2014).

[37] M.A.F. Souza, E. Denis e J.C.L. Fernandes, in Proceedings of XLIII Congresso Brasileiro de Educação em Engenharia (ABENGE, São Bernardo do Campo, 2015).

[38] L.L. Gianesini, R.C. Silva e W.R. Fernandes, in Proceedings of Computer on the Beach, (UNIVALI, Santa Catarina, 2017).

[39] https://www.lawrencehallofscience.org/, acessado em 24/06/2019.

[40] https://www.exploratorium.edu/ acessado em 24/06/2019.

[41] E.V. Rodrigues, H.R. Teles e G.G. Camiletti, Caderno Brasileiro de Ensino de Física 35, 660 (2018).

[42] G. Delacôte, Science 280, 2054 (1998).

[43] https://www.raspbian.org/, acessado em 24/06/2019.
[44] D. Lavino, Programa em Pyton para stop motion no ensino de Física, disponível em https://github.com/ dlavino/stopmotion 2017.

[45] https://youtu.be/pAHvDPTEryI, acessado em 24/06/2019. 